\title{
Clinical Characteristics of SARS-CoV-2 pneumonia diagnosed in a primary care practice in Madrid (Spain)
}

\section{Marina Guisado-Clavero}

Centro de Salud Federica Montseny.Servicio Madrileño de Salud

Ana Herrero Gil

Centro de Salud Federica Montseny.Servicio Madrileño de Salud

Marta Pérez Álvarez

Centro de Salud Federica Montseny. Servicio Madrileño de Salud

Marta Castelo Jurado

Servicio Madrileño de Salud

Ana Herrera Marinas

Servicio de Urgencias. Hospital Infanta Leonor

Vanesa Aguilar Ruiz

Centro de Salud Federica Montseny.Servicio Madrileño de Salud

lleana Gefaell larrondo

Centro de Salud Federica Montseny.Servicio Madrileño de Salud

Miguel Menéndez

Instituto de Investigacion Hospital 12 de Octubre

Sara Ares-Blanco ( $\square$ sara.ares@salud.madrid.org )

Servicio Madrileño de Salud https://orcid.org/0000-0002-4984-8788

Research article

Keywords: COVID-19, SARS-CoV-2, pneumonia, Primary Care.

Posted Date: October 22nd, 2020

DOI: https://doi.org/10.21203/rs.3.rs-42357/v2

License: (a) (i) This work is licensed under a Creative Commons Attribution 4.0 International License. Read Full License 


\section{Abstract}

Background: Possible cases of SARS-CoV-2 infection were diagnosed in primary care in Madrid, some of these cases had pneumonia. Most of the SARS-CoV-2 pneumonia published data came from hospitalised patients. This study set out to describe clinical characteristics of patients with SARS-CoV-2 pneumonia diagnosed in primary care across age groups and type of pneumonia.

Methods: Observational retrospective study obtaining clinical data from the electronic health records of patients who were followed-up by SARS-CoV-2 possible infection in a primary care practice in Madrid. All the cases were collected by in-person or remote consultation during the 10th March to the 7th of April. Exposure: Diagnosis of SARS-CoV-2 pneumonia by chest X-ray ordered by the GP. Main outcomes and measures: Symptoms of SARS-CoV-2 pneumonia, physical examination and diagnostic tests as a blood test, nasopharyngeal swab results for RT-PCR (Reverse transcriptase-polymerase chain reaction) and chest X-ray results.

Results: The overall SARS-CoV-2 pneumonias collected were 172 (female 87 [50.6\%], mean age 60.5 years (standard deviation [SD] 17.0). Comorbidities were body mass index $\geq 25 \mathrm{~kg} / \mathrm{m} 2$ (90 [52.3\%]), hypertension 83 [48.3\%]), dyslipidaemia (68 [39.5\%]) and diabetes (33 [19.2\%]). The sample was stratified by age groups ( $<50$ years, $50-75$ years and $\geq 75$ years). Clinical manifestations at onset were fever (144 [83.7\%]), cough (140 [81.4\%]), dyspnoea (103 [59.9\%]) and gastrointestinal disturbances (72 [41.9\%]). Day 7.8 (SD:4.1) from clinical onset was the mean day of pneumonia diagnosis. Bilateral pneumonia was more prevalent than unilateral (126 [73.3\%]) and 46 [26.7\%]). Patients with unilateral pneumonia were prone to higher pulse oximetry ( $96 \%$ vs $94 \%, p<0.001)$. We found differences between unilateral and bilateral cases in C-reactive protein $(29.6$ vs $81.5 \mathrm{mg} / \mathrm{L}, \mathrm{p}<0.001)$, and lymphocytes ( 1400.0 vs $1000.0 \mathrm{E} 3 / \mathrm{ml}, \mathrm{p}<0.001)$. Complications were registered: $42(100 \%)$ of patients $\geq 75$ years were admitted into hospital; pulmonary embolism was only present at bilateral pneumonia (7 patients [5.6\%]) and death occurred in 1 patient with unilateral pneumonia $(2.2 \%)$ vs 10 patients $(7.9 \%)$ with bilateral pneumonia ( $\mathrm{p} 0.170)$.

Conclusion: Clinical manifestations of SARS-CoV-2 pneumonia were fever, cough and dyspnoea; this was especially clear in the elderly. We described different characteristics between unilateral and bilateral pneumonia.

\section{Background}

The infection by the novel coronavirus SARS-CoV-2 virus is known as COVID-19 (1). The World Health Organization declared the SARSCoV-2 infection a pandemic on March $11^{\text {th }}, 2020$. Two days later, the Spanish government announced community transmission in the country and declared a national lockdown (2-4).

The incubation period of SARS-CoV-2 can vary from 2 to 14 days (5). Almost $80 \%$ of infected people had mild symptoms or were asymptomatic. and $20 \%$ presented with severe symptoms which required hospital assistance (6). Mild SARS-CoV-2 disease did not require hospital admissions, but these cases could transmit the virus (7). The most commonly reported symptoms were fever, dry cough and dyspnoea, but it could be suspected if a patient referred digestive symptoms as diarrhoea or nausea, cutaneous exanthema or even neurosensory symptoms as headache, anosmia or ageusia $(5,8,9)$. Severe symptoms developed between day 7 and day 9 from the clinical onset with typical symptoms like fever, dyspnoea and pneumonia in the chest X-ray (9).

Spain reported 250,273 total cases till the $21^{\text {st }}$ of May, confirmed by detection of viral RNA via reverse transcription-polymerase chain reaction (RT-PCR), of which 53,8\% developed SARS-CoV-2 pneumonia and $6.8 \%$ acute respiratory distress syndrome (10).

Other SARS-CoV-2 infection features were the dissociation between physical examination and chest X-ray findings described in hospital data (11). Also, the most common laboratory characteristics in SARS-CoV-2 cases were high C-reactive protein (CRP) $(58.3 \%, 95 \% \mathrm{Cl} 21.8-$ $94.7 \%)$, lymphopenia $(43.1 \%, 95 \% \mathrm{Cl} 18.9-67.3)(12)$, increased fibrinogen and D-dimer $(9,13)$. These last parameters had been suggested as risk factors for worst outcomes in SARS-CoV-2 infection; related to thromboembolism $(14,15)$. Finally, some comorbidities had been reported as risk factors for poor prognosis like hypertension, diabetes, obesity, cardiovascular and respiratory chronic diseases $(13,16,17)$.

In the European Surveillance System, Spain has been on the top three of most COVID-19 official cases reported (18). Variations throughout countries could be related to differences in health care systems. Strong primary health care not only has been associated with better health outcomes in chronic diseases (19) but with offering patient-centred care (20). In Spain, primary care has been key to detect presymptomatic and symptomatic cases. In the Madrid region, early detection of close contacts from infected cases and mild cases were followed by their primary care practice (PCP) from the outbreak onset. Despite the role of PCP to control the SARS-CoV-2 outbreak in the community, the literature about outpatient SARS-CoV-2 cases is scarce in primary care. As GPs we wanted to know when SARS-CoV-2 pneumonia appeared and which symptoms and signs could help us to identify it earlier. Thus, the study aimed to describe the 
characteristics of patients who were diagnosed of pneumonia associated with SARS-CoV-2 in a PCP in Madrid (Spain) and to compare differences across the ages as well as between unilateral versus bilateral pneumonia presentations.

\section{Methods}

Study design: A retrospective observational study was conducted at Federica Montseny PCP at Madrid. This PCP is responsible to attend 21,814 people, 172 patients were included in this study (Figure 1). The information was obtained from the electronic health record (EHR). The pneumonia cases due to SARS-CoV-2 infection were collected from those patients classified as possible cases who were examined by the PCP from the $10^{\text {th }}$ of March to the $7^{\text {th }}$ of Abril of 2020. Patients were eligible for the study if they were over 14 years old and the SARS-CoV-2 pneumonia was diagnosed by their family doctors at PCP. We excluded patients whose diagnosis was made directly at the hospital without PCP intervention and those who did not belong to Federica Montseny PCP.

SARS-CoV-2 protocol in Madrid region: Patients were encouraged to phone their PCP and stay at home until their general practitioner (GP) phoned them on the same day. In mild cases, patients received followed-up appointments at home by remote assessment using daily phone calls. In the case their symptoms worsened, they were advised to come to the PCP for examination where GPs would recommend taking a chest X-ray to rule out pneumonia. The criteria for requiring a chest X-ray were any COVID-19 progression symptom: persistent cough, thoracic pain, dyspnoea, persistent corporal temperature $\left(T>37.3^{\circ}\right)$ or physical abnormalities (tachypnoea, pulse oximetry $\leq 93 \%$, abnormal lung auscultation).The X-ray department was in the same building than our practice. If pneumonia was diagnosed, the patient was referred to Accident and Emergency department (A\&E) for laboratory tests and treatment. Mild pneumonia cases were followed-up by the PCP in conjunction with A\&E team. Mild pneumonia was defined mainly as unilateral pneumonia as well as some cases of bilateral pneumonia with local patchy opacities; these patients did not have comorbidities; they were stable with good oximetry and without bad prognosis signs in their laboratory findings. The severe cases were referred straight to the A\&E by their GPs. RT-PCR was not accessible at primary care so patients were referred to A\&E department at the diagnosis to be tested, some of the patients were admitted in hospitals where we coudn't check the RT-PCR result.

Variables: The main result was the type of pneumonia: unilateral or bilateral defined by chest X-ray results. Other variables were sociodemographic, comorbidities, prescribed chronic drugs, clinical characteristics of SARS-CoV-2 infection and laboratory results.

Statistical Analysis: Descriptive analyses were carried out for demographic, personal background, physical examination and diagnostic tests, treatment and consequences of SARS-CoV-2 infection. Quantitative variables were expressed as means with standard deviation (SD) or by medians with interquartile range (IRQ), qualitative variables were expressed as percentages. Differences were evaluated using Chi-square test for categorical variables, T-test or ANOVA for normally distributed variables and Wilcoxon-Mann-Whitney or Kruskal-Wallis test for non-normal variables. For all the statistical analyses, $p$-value $(p)<0.05$ was considered significant. Data were stratified by age group ( $<50$ years, $50-75$ years, $\geq 75$ years) and pneumonia unilateral or bilateral. All data were anonymised following national and international laws. All analyses were performed using STATA 16 and R 3.4.4.

\section{Results}

The PCP diagnosed and followed-up 1,023 patients with clinical symptoms of SARS-CoV-2 infection, SARS-CoV-2 pneumonia was present in 172 of those patients (Figure 1). As shown in Table 1, 87 (50.6\%) of the patients were female. The mean age of these 172 patients was 60.5 years. The most frequent comorbidities were body mass index $\geq 25 \mathrm{Kg} / \mathrm{m}^{2}$ (BMI) (90 patients [52.3\%]), hypertension (83 patients [48.3\%]), dyslipidaemia (68 patients [39.5\%]) and type 2 diabetes (33 patients [19.2\%]). As expected, comorbidities increased with the patient's age; being those $\geq 75$ years who had a higher burden of disease. The prevalence of lung thromboembolism was $4.1 \%$ (7 patients) without differences across the age distribution or sex, however, death was related to age (2 patients [2\%] in 50-75 years old vs 9 patients $[21 \%]$ of $\geq 75$ years and no deaths $<50$ years).

Table 1.- Clinical characteristics of SARS-CoV-2 pneumonia stratified by age groups. 
Age groups:

Total number, n (\%)

Sociodemographic variables

Age, mean (SD), years

Sex, n (\%)

$$
\begin{gathered}
\text { Female } \\
\text { Male }
\end{gathered}
$$

All

$172(100)$
$<50$ years

48 (27.9)
50-75 years

$82(47.7)$ $\geq 75$ years $\quad p$ value

$42(24.4)$
$60.5(17.0)$

$87(50.6)$

$85(49.4)$
$39.0(8.3)$

$25(52.0)$

$23(48.0)$
$62.1(6.5)$

32 (39)

50 (61)
$81.9(5.5)$

30 (71)

$12(29)$

\section{Comorbidities}

Cardiovascular risk factor

$\begin{array}{cccccc}\text { Smoke habit, } \mathrm{n}(\%) & 13(7.6) & 3(6) & 10(12) & 0(0) & 0.062 \\ \mathrm{BMI} \geq 25 \mathrm{Kg} / \mathrm{m} 2, \mathrm{n}(\%) & 90(52.3) & 16(33) & 51(62) & 23(55) & 0.012 \\ \text { Hypertension, } \mathrm{n}(\%) & 83(48.3) & 6(12) & 39(48) & 38(90) & <0.001 \\ \text { type 2 Diabetes, } \mathrm{n}(\%) & 33(19.2) & 0(0) & 21(26) & 12(29) & <0.001 \\ \text { Dyslipidemia, } \mathrm{n}(\%) & 68(39.5) & 11(23) & 32(39) & 25(60) & 0.002\end{array}$

Respiratory diseases

$\begin{array}{cccccc}\text { Asthma, } \mathrm{n}(\%) & 21(12.2) & 4(8) & 7(9) & 10(24) & 0.031 \\ \text { COPD, } \mathrm{n} \mathrm{( \% )} & 9(5.2) & 1(2) & 5(6) & 3(7) & 0.50\end{array}$

Cardiovascular diseases

Ischaemic heart diseases, $\mathrm{n}$ $(\%)$

Arrhythmias, n (\%)

$9(5.2)$

$0(0)$

$3(4)$

6 (14)

0.007

$10(5.8)$

$1(2)$

$2(2)$

7 (17)

0.003

Heart failure, n (\%)

$0(0)$

$3(4)$

$4(10)$

0.072

Other diseases

Chronic kidney diseases

Cognitive impairment, $\mathrm{n}(\%)$ Cancer, $\mathrm{n}(\%)$

$12(7.0)$

$0(0)$

$3(4)$

$9(21)<0.001$

$10(5.8)$

$1(2)$

1 (1)

8 (19)

$<0.001$

Rheumatological diseases, $\mathrm{n}$

$10(5.8)$

$0(0)$

4 (5)

$6(14)$

0.014

(\%)

$14(8.1)$

$3(6)$

6 (7)

5 (12)

0.58

\section{Chronic treatment}

no drugs, $\mathrm{n}(\%)$

1-4 drugs, n (\%)

5-9 drugs, $n(\%)$

$\geq 10$ drugs, $\mathrm{n}(\%)$
$33(19.2)$

68 (39.5)

$43(25.0)$

28 (16.3)
$19(40)$

$25(52)$

3 (6)

$1(2)$
$14(17)$

$35(43)$

$20(24)$

$13(16)$
$0(0)$

8 (19)

$20(48)$

$14(33)$

\section{Antithrombotic/anticoagulant}

\section{treat.}

Antithrombotic drug, n (\%)

Anticoagulant drug, n (\%)

Non consumption, $\mathrm{n}(\%)$

\section{$14(8.1)$ \\ $8(4.7)$}

$150(87.2)$
$1(2)$

1 (2)

$46(96)$

$7(9)$
$2(2)$
$73(89)$

$6(14)$

$5(12)$

$31(74)$
0.019

\section{Symptoms}

Fever, n (\%)

Cough, n (\%)

Dyspnea, $\mathrm{n}(\%)$

Gastrointestinal disturbances, $\mathrm{n}(\%)$

Myalgias, n (\%)

Thoracic Pain, $\mathrm{n}(\%)$

Pleural chest Pain, n (\%)

Rhinitis, $\mathrm{n}(\%)$

Odynophagia, n (\%)

Asthenia, n (\%)

Headache, n (\%)

Dysgeusia, $\mathrm{n}(\%)$

Anosmia, n (\%)

$\begin{array}{ccc}144(83.7) & 41(85) & 74(90) \\ 140(81.4) & 43(90) & 68(83) \\ 103(59.9) & 29(60) & 50(61) \\ 72(41.9) & 23(48) & 32(39) \\ 51(29.7) & 15(31) & 30(37) \\ 27(15.7) & 17(35) & 9(11) \\ 10(5.8) & 4(8) & 6(7) \\ 8(4.7) & 4(8) & 4(5) \\ 20(11.6) & 8(17) & 8(10) \\ 47(27.3) & 13(27) & 20(24) \\ 47(27.3) & 13(27) & 20(24) \\ 9(5.2) & 6(12) & 3(4) \\ 2(1.2) & 1(2) & 1(1)\end{array}$

$20(42)$

$28(58)$
41 (51)

40 (49)

$\begin{array}{cc}29(69) & 0.003 \\ 29(69) & 0.039 \\ 24(57) & 0.91 \\ 17(40) & 0.60 \\ 6(14) & 0.035 \\ 1(2) & <0.001 \\ 0(0) & 0.17 \\ 0(0) & 0.17 \\ 4(10) & 0.44 \\ 14(33) & 0.57 \\ 14(33) & 0.57 \\ 0(0) & 0.020 \\ 0(0) & 0.65\end{array}$

$36(86)$

$<0.001$
$1-3$ total symptoms, $\mathrm{n}(\%)$
$\geq 4$ total symptoms, $\mathrm{n}(\%)$

$97(56.7)$
$<0.001$

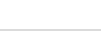




\section{Physical examination}

Temperature, median (IQR), ${ }^{\circ} \mathrm{C}$

Heart rate, mean (SD), bpm

Respiratory rate, (median (IQR), rpm

Pulse oximetry, median (IQR), $\%$

Normal lung auscu

$37.2(36.7,37.8)$
$93.2(16.1)$

$37.3(0.8)$

$99.6(13.8)$

$16.0(15.0,21.0)$

$16.0(15.0,16.0)$

$94.0(92.0,96.5)$

$96.0(94.0,97.5)$
$37.4(0.8)$

93.3 (16.5)

$18.0(15.5,21.0)$

$94.0(92.0,96.0)$
$37.0(0.8)$

$85.9(15.1)$

$22.0(15.0,25.0)$

$92.0(88.5,94.0)<0.001$
13 (27)

$12(25)$
$21(26)$

24 (29)
4 (10)

0.16

$54(31.4)$

$18(43)$

0.16

(\%)

\section{Blood test}

CRP, median (IQR), mg/L

Lymphocytes, median (IQR), $10 \mathrm{e} 3 / \mathrm{ml}$

$65.3(29.0,128.0) \quad 57.0(12.8,115.0)$

$60.9(34.0,135.0)$

$81.5(45.0,133.0) \quad 0.32$ $1100.0(800.0$, $1500.0)$ $1250.0(1000.0$ $445.0(288.0$

D-Dimer, median (IQR), $\mu \mathrm{g} / \mathrm{L}$ 910.0) $1000.0(800.0$,

Fibrinogen $\geq 500$, n (\%), $\mathrm{mg} / \mathrm{dL}$

127 (73.8)

$443.5(200.0$,

Ferritin, median (IQR), $\mu \mathrm{g} / \mathrm{L}$ $1750.0)$ $410.0(240.0$, 901.5) 1400.0) $460.0(270.0$, 880.0)

31 (65)

474.0 (320.0, 1738.0)
$62(76)$

494.0 (203.0, 913.0)

\section{RT-PCR SARS-CoV-2}

Negative, $\mathrm{n}(\%)$

Positive, n (\%)
36 (20.9)

$122(70.9)$
17 (35)

$27(56)$
13 (16)

$64(78)$
$900.0(600.0$, 1200.0) $\quad 0.002$

464.0 (320.0, 2160.0)

0.39

$34(81)$

$325.5(184.5$ 1006.5)

\section{Pneumonia features}

Pneumonia onset, mean (SD),

$$
\text { days }
$$

Unilateral, n (\%)

Bilateral, n (\%)

$7.8(4.1)$

46 (26.7)

$126(73.3)$
$8.1(4.7)$

$21(44)$

$27(56)$
$140(81.4)$

$7(4.1)$ $11(6.4)$
$30(62)$

$2(4)$ $0(0)$
$8.3(3.8)$

$19(23)$

63 (77)
6 (14)

$31(74)$
0.041

0.042

\section{Complications}

Hospital admission, $\mathrm{n}(\%)$
Pulmonary thromboembolism, n (\%)
Death, n (\%) $68(83)$ $42(100)$ $<0.001$

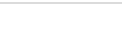

(a)

(n)

$\begin{array}{cccc}2(4) & 2(2) & 3(7) & 0.45 \\ 0(0) & 2(2) & 9(21) & <0.001\end{array}$

Footnotes n: number, SD: standard deviation, BMI: body mass index, COPD: chronic obstructive pulmonary disease, IQR: interquartile range, CRP: C-reactive protein, RT-PCR: reverse transcription PCR, bmp: beats per minute, rpm: respiratory rate per minute

\section{Clinical manifestations}

Fever (144 patients [83.7\%]) and cough (140 patients [81.4\%]) were the most prevalent symptoms followed by dyspnoea (103 patients [59.9\%]) and gastrointestinal disturbances (72 patients [41.9\%]). We did not only describe the evolution of the symptoms during the infection till the onset of pneumonia (Figure 2) but also across the different age groups (Figure 3); we found myalgia and asthenia also common symptoms in the evolution. A box plot of pneumonia is represented on the bottom of Figure 2, locating the median diagnosed day in the day 7 of clinical onset and the $50 \%$ of the sample from the day 5 to day 10 .

We found clinical differences in the pneumonia syndrome among the different ages; not only did $\geq 75$ years have 1-3 symptoms (36 patients [86.0\%]) more than $<50$ years (20 patients [42.0\%]) $(p<0.001)$ but their pneumonia onset was earlier, with a mean day 6.7 (SD 3.7$)$ than the other groups (day 8.1 (SD 4.7) in $<50$ years and day 8.3 (SD 3.8) in 50-75 years respectively). The group of $<50$ years described $\geq 4$ symptoms in 28 patients (58.0\%) compared to the other groups (40 patients [49.0\%] in 50-75 years and 6 patients [ $14.0 \%]$ in $\geq 75$ years) $(p<0.001)$. The full description of the patients who did not survive can be checked in additional file 1. 
The physical examination was not completed in all the cases; pulse oximetry was recorded in 162 patients (94.1\%), heart rate in 138 patients $(80.2 \%)$, the temperature in 131 patients $(76.1 \%)$, lung auscultation in 92 patients $(53,4 \%)$ and respiratory rate in 60 patients (34.8\%). Basal pulse oximetry had a median value of $94.0 \%$ (IQR 92.0, 96.5), the median temperature was $37.2^{\circ} \mathrm{C}($ IQR $36.7,37.8)$. Statistically significant differences in pulse oximetry across the different ages and also the survivors versus no survivors were found. Patients $\geq 75$ years had the lowest values $(92.0 \%)$ compared to $<50$ years $(96.0 \%)$ and $50-75$ years $(94.0 \%)$ (Table 1$)$. We also found differences comparing non-survivors with survivors ( $91.0 \%$ vs $94.0 \%$ ) (Additional file 1 ). The pulse oximetry was $\geq 94 \%$ in 98 patients $(57.0 \%)$ of the whole population, that was achieved by 37 patients $(77.0 \%)$ of $<50$ years group, 48 patients (59.0\%) of $50-75$ years but only 13 patients $(31.0 \%)$ of $\geq 75$ years group. We did not find differences in the auscultation, respiratory rate or temperature in the different ages.

Regarding the laboratory test, we did not find differences in the values except in lymphocytes. The median value for lymphocytes was $1100.0 \mathrm{E} 3 / \mathrm{ml}$, (IQR 800.0, 1500.0). The values were decreasing with age from 1250E3/ml (IQR 1000.0, 1750.0) in <50 years, 1000.0 (IQR $800.0,1400.0)$ in $50-75$ years to $900 \mathrm{E} 3 / \mathrm{ml}(600.0,1200.0)$ in the $\geq 75$ years group $(p 0.002)$.

Nasopharyngeal swab was obtained to confirm SARS-CoV-2 infection in $91.8 \%$ of patients ( $\mathrm{n}: 158)$ and it was positive in $70.9 \%$ of patients. A negative result was more frequent in $<50$ years with 17 patients $(35 \%)$ compared to $\geq 75$ years group with 6 patients (14\%) as well as a positive result was more common in patients $\geq 75$ years group with 31 patients $(74 \%)$ compared to those $<50$ years with 27 patients (56\%) ( $p$ 0.041).

\section{Unilateral versus Bilateral pneumonia:}

Unilateral pneumonia was present at 46 patients (26.7\% [95\% confidence interval (Cl) $20.3 \%-33.4 \%$ ]) of the cases while bilateral pneumonia was found on 126 patients $(73.3 \%$ [95\% $\mathrm{Cl} 66.9 \%-79.9 \%])$ of the sample. We observed differences between the mean age in patients with unilateral versus bilateral pneumonia (53.7 vs 63.0 years) (Table 2). Patients with bilateral pneumonia had more comorbidities, however we only found statistical significance in hypertension (16 patients [34.8\%] in unilateral pneumonia vs 67 patients [53.2\%] in bilateral pneumonia, $p$ 0.033), type 2 diabetes ( 4 patients [8.7\%] in unilateral pneumonia vs 29 patients [23.0 \%] in bilateral pneumonia, $p 0.035$ ) or chronic kidney disease (no patients in unilateral pneumonia vs 12 patients [9.5\%] in bilateral pneumonia, $p$ 0.030). Patients with unilateral pneumonia presented more frequently myalgia (17 patients [37.0\%]) and chest pain (10 patients [21.7\%]). Bilateral pneumonia had more dyspnoea (79 patients [62.7\%]), but no significant differences were found in clinical characteristics. On the one hand, patients with unilateral pneumonia were prone to normal auscultation compared to bilateral cases (16 patients [34.8\%] vs 22 patients [17.5\%], $p$ 0.014) and higher pulse oximetry ( $96 \% \mathrm{vs} 94 \%, p<0.001)$. We found statistical significance between unilateral and bilateral cases in CRP (29.6 vs $81.5 \mathrm{mg} / \mathrm{L})$, lymphocytes ( $1400.0 \mathrm{vs} 1000.0 \mathrm{E} 3 / \mathrm{ml})$ and fibrinogen $\geq 500 \mathrm{mg} / \mathrm{dL}$ (24 patients [52.2\%] vs 103 [81.7\%]). Unilateral pneumonia had more negative RT-PCR, 17 patients (37.0\%) vs 19 patients (15.1\%) of bilateral ones $(p 0.006) .20$ patients (43.5\%) with unilateral pneumonia required hospital admission in comparison to 120 patients (95.2\%) of bilateral pneumonia however pulmonary embolism was only present at bilateral pneumonia (7 patients [5.6\%]). Death was present chiefly on bilateral cases (1 patient in unilateral cases [2.2\%] 10 patients [7.9\%]) (Table 2).

Table 2.- Differences between SARS-CoV-2 pneumonia patterns: unilateral and bilateral. 
Pneumonia

Number (\%)

Pneumonia onset, mean (SD), days
Unilateral

$46(26.7)$

$8.2(5.1)$
Bilateral

$p$-value

$126(73.3)$

$7.7(3.7)$

0.47

\section{Sociodemographic variables}

Age, mean (SD), years

Sex, n (\%)

Female
Male

$28(60.9)$

$53.7(16.6)$

Male
$18(39.1)$

$63.0(16.6)$

$59(46.8)$

0.10

\section{Comorbidities}

Cardiovascular risk factor

$$
\text { Smoke habit, n (\%) }
$$

$\mathrm{BMI} \geq 25 \mathrm{Kg} / \mathrm{m} 2, \mathrm{n}$ (\%)

$4(8.7)$

$9(7.1)$

0.38

Hypertension, n (\%)

type 2 Diabetes, n (\%)

Dyslipidemia, n (\%)

Respiratory diseases

20 (43.5)

$70(55.6)$

0.25

$16(34.8)$

67 (53.2)

0.033

$4(8.7)$

$29(23.0)$

0.035

$15(32.6)$

$53(42.1)$

0.26

Cardiovascular diseases

$0(0.0)$

0.030

$$
\begin{aligned}
& \text { Asthma, n (\%) } \\
& \text { COPD, n (\%) }
\end{aligned}
$$$$
4 \text { (8.7) }
$$

Ischaemic heart diseases, $\mathrm{n}(\%)$

$1(2.2)$
$1(2.2)$
$2(4.3)$

$12(9.5)$

Cognitive impairment, n (\%)

Cancer, n (\%)

$3(6.5)$

$1(2.2)$

2 (4.3)

17 (13.5)

0.40

$6(4.8)$

0.65

Rheumatological diseases, n (\%)

$8(6.3)$

0.28

$9(7.1)$

0.22

$5(4.0)$

0.91

Chronic kidney diseases, n (\%)

$7(5.6)$

0.81

$9(7.1)$

0.22

$12(9.5)$

0.27
Other diseases

\section{Chronic treatment}

$$
\begin{aligned}
& \text { no drugs, n (\%) } \\
& 1 \text {-4 drugs, n (\%) } \\
& 5-9 \text { drugs, n (\%) } \\
& \geq 10 \text { drugs, n (\%) }
\end{aligned}
$$$$
8(17.4)
$$$$
25(19.8)
$$$$
21(45.7)
$$$$
47(37.3)
$$$$
12(26.1)
$$$$
31(24.6)
$$

$5(10.9)$

Antithrombotic/anticoagulant treatment

Antithrombotic drug, n (\%)

Anticoagulant drug, n (\%)

Non consumption, $\mathrm{n}(\%)$
$1(2.2)$

$2(4.3)$

43 (93.5)

Page $7 / 14$
$13(10.3)$

0.22 


\section{Symptoms}

$\begin{array}{cccc}\text { Fever, } \mathrm{n}(\%) & 38(82.6) & 106(84.1) & 0.81 \\ \text { Cough, n (\%) } & 37(80.4) & 103(81.7) & 0.84 \\ \text { Dyspnea, n (\%) } & 24(52.2) & 79(62.7) & 0.21 \\ \text { Gastrointestinal disturbances, n(\%) } & 18(39.1) & 54(42.9) & 0.66 \\ \text { Myalgias, n (\%) } & 17(37.0) & 34(27.0) & 0.20 \\ \text { Thoracic Pain, n (\%) } & 10(21.7) & 17(13.5) & 0.19 \\ \text { Pleural chest Pain, n (\%) } & 6(13.0) & 4(3.2) & 0.014 \\ \text { Rhinitis, n (\%) } & 4(8.7) & 4(3.2) & 0.13 \\ \text { Odynophagia, n (\%) } & 7(15.2) & 13(10.3) & 0.37 \\ \text { Asthenia, n (\%) } & 12(26.1) & 35(27.8) & 0.83 \\ \text { Headache, n (\%) } & 12(26.1) & 35(27.8) & 0.83 \\ \text { Dysgeusia, n (\%) } & 3(6.5) & 6(4.8) & 0.65 \\ \text { Anosmia, } \mathrm{n}(\%) & 1(2.2) & 1(0.8) & 0.45\end{array}$

\section{Symptoms categorized}

1-3 total symptoms, n (\%)

$\geq 4$ total symptoms, n (\%)
$25(54.3)$

$21(45.7)$
$72(57.6)$

0.70

\section{Physical examination}

Temperature, mean (SD), ${ }^{\circ} \mathrm{C}$

Heart rate, mean (SD), bpm

Respiratory rate, median (IQR), rpm

Pulse oximetry, median (IQR), \%

Normal lung auscultation, n (\%)

Abnormal lung auscultation, n (\%)

$37.2(0.8)$
$96.2(15.1)$
$16.0(14.0,16.0)$
$96.0(94.0,97.0)$
$16(34.8)$
$8(17.4)$

$37.3(0.8)$

0.86

$92.2(16.4)$

0.20

$17.0(15.0,22.0)$

0.073

$94.0(91.0,96.0)$

$<0.001$

$22(17.5)$

0.014

$46(36.5)$

0.014

\section{Blood test}

CRP, median (IQR), mg/L

Lymphocytes, median (IQR), 10e3/ml

D-Dimer, median (IQR), $\mu \mathrm{g} / \mathrm{L}$ Fibrinogen $\geq 500, \mathrm{n}(\%), \mathrm{mg} / \mathrm{dL}$

Ferritin, median (IQR), $\mu \mathrm{g} / \mathrm{L}$
$29.6(5.0,81.5)$

$1400.0(1100.0,1880.0)$

$339.0(197.0,464.0)$

24 (52.2)

$618.0(280.5,919.0)$

$\begin{array}{cc}81.5(46.2,143.0) & <0.001 \\ 1000.0(800.0,1400.0) & <0.001 \\ 520.0(320.0,1030.0) & 0.035 \\ 103(81.7) & <0.001 \\ 424.0(200.0,1215.0) & 0.96\end{array}$

\section{RT-PCR SARS-CoV-2}

Negative, n (\%)

Positive, n (\%)
17 (37.0)

25 (54.3)
$19(15.1)$

0.006 


\section{Complications}

Hospital admission, n (\%)

Pulmonary thromboembolism, n (\%)

Death, n (\%)
$20(43.5)$

$0(0.0)$

$1(2.2)$
$120(95.2)$

7 (5.6)

$<0.001$

$10(7.9)$
0.10

0.17

Footnotes n: number, SD: standard deviation, BMI: body mass index, COPD: chronic obstructive pulmonary disease, IQR: interquartile range, CRP: C-reactive protein, RT-PCR: reverse transcription PCR, bpm: beats per minute, rpm: respiratory rate per minute

\section{Discussion}

In this study, females were $50.3 \%$ of the population. The age distribution was asymmetric, however non-survivors belonged mainly to the elderly. The most prevalent comorbidities were hypertension, dyslipidaemia and BMI $\geq 25 \mathrm{Kg} / \mathrm{m}^{2}$. Clinical manifestations of SARS-CoV-2 pneumonia were fever and cough as the main symptoms, most of the patients had only 1-3 symptoms; this was especially clear in the elderly ( $\geq 75$ years) whose clinical presentation was mainly with 1-3 symptoms. We described different characteristics between unilateral and bilateral pneumonia.

Some publications have been reporting age as a factor for developing severe illness due to SARS-CoV-2 infection (13), our study is consistent with this observation because elderly patients had more frequently bilateral pneumonia and also morbidity compared to younger patients. These findings are in concordance to Liu et al. who found more bilateral pneumonia in older patients (21). However, elderly presented fewer symptoms than those younger than 75 years because they used to have less pneumonia symptoms (22) and also their own comorbidities could overlap some COVID-19 symptoms. The comorbidities of our population (hypertension, dyslipidemia, diabetes and $\mathrm{BMI} \geq 25 \mathrm{Kg} / \mathrm{m}^{2}$ ) were similar to the studies that have been published $(13,17)$. These results are consistent with a metaanalysis published by Yang et al. (16), they found that patients infected by SARS-CoV-2 had hypertension (21.1\%) and diabetes (9.7\%) as the most prevalent comorbidities. Smoking was present in $7.5 \%$ of our population, less than others. Guan et al (6) reported $12.6 \%$ in smokers, that difference could be explained by incomplete EHR.

In this study, we described the symptoms and their chronology up until the appearance of pneumonia. We were interested in describing clinical patterns that could help us to decide when to request a chest X-ray and how to detect pneumonia. As expected, we found fever (83.8\%), cough (81.5\%), dyspnea (59.5\%) and myalgia $(30,1 \%)$ as the most frequent symptoms, consistent with the literature (9,12) and with Sun et al (23) who reported fever $(89,1 \%)$ and cough $(72.2 \%)$ as the most frequent symptoms; the differences among their percentages and ours could be explained by the accuracy in the EHR because the record was made daily.

We collected 12 symptoms, fever, cough and dyspnea were the most frequent, consistent with the meta-analysis of Rodriguez et al. who reported fever $(88.7 \%, 95 \% \mathrm{Cl} 84.5-92.9 \%)$, cough $(57.6 \%, 95 \% \mathrm{Cl} 40.8-74.4 \%)$ and dyspnea $(45.6 \%$, 95\% Cl 10.9-80.4\%). We observed that most of the patients exhibited only 1-3 symptoms (56.1\%). In our study the elderly had fewer symptoms, which is consistent with Niu et al. (24) who described less dyspnoea and cough in patients over 80 years however in their study fever $\left(\geq 37,3^{\circ} \mathrm{C}\right)$ was more prevalent than in our study (75\% vs 69\%); maybe this could be explained by the different age ranges (in their case: $50-64,65-79$ and $\geq 80$ years).

In this study, the diagnosis of pneumonia was on day 7.8 of onset of the symptoms, similar to Wang et al. (25) where at hospital admission had a median on day 7.0 (IQR 4.0,8.0). These periods were longer than other publications which established the diagnosis through day 3.0 (IQR 1.0,6.0) for non-severe SARS-CoV-2 infection but on day 5.0 (IQR 2.0,7.0) in severe infections (6). Our study found that the diagnosis in the elderly group was made on day 6.7 of the onset. Furthermore, this group had more deaths (21\%) and they were the ones who suffered more severe disease. They had tachypnoea, $92 \%$ of pulse oximetry, $43 \%$ of abnormal auscultation as well as more abnormalities in their blood tests. Most manuscripts published did not compare the differences across age groups because they were focused on severe and not severe cases. Niu et al. described $90.6 \%$ of oximetry and death in 18.8 of their $\geq 80$ years patients which is similar to our results.

On another note, the physical examination was not recorded in all patients. At the moment, we still do not know the predictive values of symptoms and physical examination in COVID-19, especially of the lung auscultation which involves physical touch. In Spain, we suffered 
a shortage of personal protective equipment (PPE) for healthcare workers $(40,921$ of healthcare workers were infected by SARS-CoV- 2 in the country till $11^{\text {th }}$ of May (10) which made doctors cautious of examining the patients if they could get a diagnosis through anamnesis and chest X-ray. If we compare with other series, Guan et al. do not detail these physical signs in their data as well as Zhou et al. who just describe respiratory rate in $29 \%$ of their patients (26). A survey (27) was conducted in Canada to explore the opinions of GPs during the SARS (2003) and H1N1 (2010) outbreaks, GPs answered that they would avoid physical examinations in patients with SARS (62\%) and patients with H1N1 (18\%). More studies should be conducted to observe the benefit of the physical examination in the management of COVID-19. This should come along with qualitative research to understand the perspective of the doctors.

We described two clinical patterns by chest X-ray: unilateral and bilateral pneumonia however, little is known about other differences between both types of pneumonia (12). In this study, $73.3 \%$ of the types of pneumonia were bilateral; our results are in concordance with Shi et al. (n:416) (28) and Chen et al. (29), where around $75 \%$ of cases of pneumonia corresponded to bilateral and $25 \%$ to unilateral. Shi et al. as well as Guan et al. described bilateral pneumonia more frequently in severe cases. Unilateral pneumonia appeared more frequently in younger patients (53.7 vs 62.8 years), the onset was slightly later than bilateral pneumonia (8.9 vs 7.8 days) and most of them did not have red flags on their examination (abnormal auscultation, oximetry $\leq 94 \%$ ) or blood tests ( CRP $\geq 81.5 \mathrm{mg} / \mathrm{L}, \mathrm{D}-\mathrm{Dimer} \geq$ $520 \mu \mathrm{g} / \mathrm{L}$, Lymphocytes $\leq 1,00010 \mathrm{e} 3 / \mathrm{L}$, Fibrinogen $\geq 500 \mathrm{mg} / \mathrm{dL})(6,28)$. They had higher oximetry ( $96 \% \mathrm{vs} 94 \%)$ and more normal auscultation (34.8\% vs $17.5 \%$ ) without differences in other physical signs or symptoms. Unilateral pneumonia presented $37 \%$ of negative RT-PCR similar to Weissleder et al. who reported 30\% (range:10-40\%) of false negative results (30). Any of our patients with unilateral pneumonia had a pulmonary embolism and just one of them did not survive.

Finally, health systems have faced significant stress because of pandemic, unfortunately more pandemic waves could happen till vaccination is available. This situation has highlighted the need for a whole patient perspective to take decisions especially when patients are assessed by remote consultation. Priority should be given to primary care who have a long-term relationship with their patients because not only they can follow them but they can manage those SARS-CoV-2 pneumonia patients without red flags in settings with access to laboratory tests and chest $\mathrm{X}$-ray. We have found that unilateral pneumonia without red flags could be monitored closely in primary care without referring patients to the hospital if they can assure follow-up tightly. We hypothesise that unilateral SARS-CoV-2 pneumonia without red flags could be managed in primary care but more research is needed to characterise these clinical patterns related to the age and unilateral vs bilateral pneumonia.

\section{Strengths and Limitations}

To our knowledge, our study is the first one to describe patients with SARS-CoV-2 pneumonia diagnosed in a PCP. Besides, we described the clinical differences between bilateral and unilateral cases of pneumonia. However, limitations of this observational study should be addressed. Firstly, this study was carried out in a unique PCP, so the results might not be wildly generalisable. The cardiovascular factors could not be updated in the EHR (especially tobacco or BMI) but the comorbidities are usually updated because we have validated the diagnosis for research with success in other studies (31). In addition, a bias should be considered because we are located in a primary health centre which include a radiology department, so that we had facilities to diagnose SARS-CoV-2 pneumonia compared to other primary health centers of Madrid. Our study described the symptoms up through the onset of pneumonia but some of unilateral pneumonia should be addressed more thoroughly. On the one hand, we have not collected whether or not they could progress to bilateral pneumonia. On the other hand, we should approach differently those unilateral pneumonia with negative RT-PCR; we should have evidence if the RT-PCR was repeated several times. Further studies should be conducted to clarify these cases. Finally, we based our pneumonia diagnosis in the radiologist description but there could be an interpersonal variability in that description.

\section{Conclusions}

SARS-CoV-2 pneumonia had mainly fever, cough and dyspnoea symptoms, particularly in the elderly. We found two clinical patterns: unilateral and bilateral pneumonia. Unilateral pneumonia appeared more frequently in younger patients without red flags in their physical examination or laboratory tests however bilateral pneumonia was more common in elderly patients with red flags. Primary care can manage mild pneumonia through anamnesis and proper diagnostic tests.

\section{Abbreviations}

A\&E: Accident and Emergency department, BMI: body mass index, Cl confidence interval, CRP: C-reactive protein, EHR: electronic health record, GP: General practictioner, IRQ: interquartile range, p: p value, PCP: primary care practice, RT-PCR: Reverse transcriptase-polymerase chain reaction, SD: Standard deviation. 


\section{Declarations}

Ethics approval and consent to participate: This study was approved by the Ethics Committee of University Hospital Gregorio Marañón (13/2020), the Primary Care Southeast Research Committee (CLISE) at Madrid region (09/20) and the Spanish Drug Agency (AEMPS). No written informed consent was obtained for children as all participants were over 18 years old.

\section{Consent for publication: Not applicable}

Availability of data and materials: The datasets generated and/or analysed during the current study are not publicly available to protect participant privacy, but are available from the corresponding author on reasonable request.

Competing interests: none declared.

Funding : This study was funded by the Fundación para la investigación e innovación biosanitaria en Atención Primaria (FIIBAP). The funder had no role in study design or in the decision to submit the report for publication

Authors' contributions: $\mathrm{SAB}, \mathrm{MGC}$ and MM had full access to all of the data in the study and take responsibility for the integrity of the data and the accuracy of the data analysis. Study concept and design SAB and MM. Acquisition, analysis, or interpretation of data: SAB, MGC, AHG, MPA, MCJ, AHM, VAR, IGI and MM. Drafting of the manuscript. MGC, SAB. Critical revision of the manuscript for important intellectual content. SAB, MM, EP and LC. Statistical analysis: SAB, MM. Administrative, technical, or material support. SAB, MGC, AHG, MPA, MCJ, AHV, VAR, IGI and MM. Supervision: MGC, SAB. All Authors read and approved the manuscript.

Acknowledgements: We would like to thank all the healthcare professionals who worked tirelessly during the SARS-CoV-2 pandemic in the Madrid region. We are especially grateful for the support of those working at Federica Montseny PHCC and University Hospital Infanta Leonor. L. Flippin, S. Collen and E. García provided professional writing services. We would like to thank E. Polentinos and L. Castelo for guidance in the revision of the manuscript.

\section{References}

1. World Health Organization: Naming the coronavirus disease (COVID-19) and the virus that causes it. https://www.who.int/emergencies/diseases/novel-coronavirus-2019/technical-guidance/naming-the-coronavirus-disease-(covid2019)-and-the-virus-that-causes-it. Accessed 27 May 2020.

2. Wang C, Horby PW, Hayden FG, Gao GF. A novel coronavirus outbreak of global health concern. Lancet. 2020 Feb;395(10223):470-3.

3. World Health Organization: WHO Director-General's opening remarks at the media briefing on COVID-19. https://www.who.int/dg/speeches/detail/who-director-general-s-opening-remarks-at-the-media-briefing-on-covid-19--11-march-2020. Accessed 27 May 2020.

4. Gobierno deEspaña: Boletín Oficial del Estado. https://www.boe.es/diario_boe/txt.php?id=BOE-A-2020-3692. Accessed 27 May 2020.

5. Sohrabi C, Alsafi Z, O’Neill N, Khan M, Kerwan A, Al-Jabir A, et al. World Health Organization declares global emergency: A review of the 2019 novel coronavirus (COVID-19). Int J Surg Apr;76:71-6.

6. Guan W-J, Ni Z-Y, Hu YY-H, Liang W-H, Ou C-Q, He J-X, et al. Clinical Characteristics of Coronavirus Disease 2019 in China. N Engl J Med. 2020 Feb 28;1-13.

7. Gandhi RT, Lynch JB, Del Rio C. Mild or Moderate Covid-19. N Engl J Med. 2020 Apr 24.

8. Diaz-Guimaraens B, Dominguez-Santas M, Suarez-Valle A, Pindado-Ortega C, Selda-Enriquez G, Bea-Ardebol S, et al. Petechial Skin Rash Associated With Severe Acute Respiratory Syndrome Coronavirus 2 Infection. JAMA Dermatology [Internet]. 2020 Apr 30;2017(C):1-3.

9. Huang C, Wang Y, Li X, Ren L, Zhao J, Hu Y, et al. Clinical features of patients infected with 2019 novel coronavirus in Wuhan, China. Lancet. 2020;395:497-506.

10. Instituto Carlos III: Informes COVID-19 https://www.isciii.es/QueHacemos/Servicios/VigilanciaSaludPublicaRENAVE/EnfermedadesTransmisibles/Paginas/InformesCOVID19.aspx.. Accessed 27 May 2020.

11. Yang W, Cao Q, Qin L, et al. Clinical characteristics and imaging manifestations of the 2019 novel coronavirus disease (COVID-19): A multi-centre study in Wenzhou city, Zhejiang, China. J Infect. 2020;80(4):388-93. 
12. Rodriguez-Morales AJ, Cardona-Ospina JA, Gutiérrez-Ocampo E, et al. Clinical, laboratory and imaging features of COVID-19: A systematic review and meta-analysis. Travel Med Infect Dis Mar;34:101623.

13. Zhou F, Yu T, Du R, Fan G, Liu Y, Liu Z, et al. Clinical course and risk factors for mortality of adult inpatients with COVID-19 in Wuhan, China: a retrospective cohort study. Lancet (London, England). 2020;6736(20):1-9.

14. Grillet F, Behr J, Calame P, Aubry S, Delabrousse E. Acute Pulmonary Embolism Associated with COVID-19 Pneumonia Detected by Pulmonary CT Angiography. Radiology. 2020 Apr 23;201544.

15. Gao Y, Li T, Han M, Li X, Wu D, Xu Y, et al. Diagnostic Utility of Clinical Laboratory Data Determinations for Patients with the Severe COVID-19. J Med Virol. 2020 Mar 17;jmv.25770.

16. Yang J, Zheng Y, Gou X, Pu K, Chen Z, Guo Q, et al. Prevalence of comorbidities and its effects in patients infected with SARS-CoV-2: a systematic review and meta-analysis. Int J Infect Dis. 2020 May;94:91-5.

17. Richardson S, Hirsch JS, Narasimhan M, Crawford JM, McGinn T, Davidson KW, et al. Presenting Characteristics, Comorbidities, and Outcomes Among 5700 Patients Hospitalized With COVID-19 in the New York City Area. Jama. 2020;10022:1-8.

18. ECDC. COVID Surveillance Report. 2020. https://www.ecdc.europa.eu/en/covid-19/situation-updates. Accessed 27 May 2020.

19. Starfield B, Shi L, Macinko J. Contribution of primary care to health systems and health. Milbank Q . 2005;83(3):457-502.

20. OECD. Realising the Potential of Primary Health Care. OECD; 2020. 1-16 p. (OECD Health Policy Studies). http://www.oecd.org/health/health-systems/OECD-Policy-Brief-Primary-Health-Care-May-2019.pdf. Accessed 27 May 2020.

21. Liu K, Chen Y, Lin R, Han K. Clinical features of COVID-19 in elderly patients: A comparison with young and middle-aged patients Journal of Infection 2020. Vol. 80, p. e14-8.

22. Fein AM. Pneumonia in the elderly: Special diagnostic and therapeutic considerations. Med Clin North Am. 1994;78(5):1015-33.

23. Sun P, Qie S, Liu Z, Ren J, Li K, Xi J. Clinical characteristics of hospitalized patients with SARS-CoV-2 infection: A single arm metaanalysis. J Med Virol. 2020 Jun 11;92(6):612-7.

24. Niu S, Tian S, Lou J, et al. Clinical characteristics of older patients infected with COVID-19: A descriptive study. Arch Gerontol Geriatr. 2020 Jul;89:104058.

25. Wang D, Hu B, Hu C, et al. Clinical Characteristics of 138 Hospitalized Patients with 2019 Novel Coronavirus-Infected Pneumonia in Wuhan, China. JAMA - J Am Med Assoc. 2020;1-9.

26. Zhang L, Zhu F, Xie L, Wang C, Wang J, Chen R, et al. Clinical characteristics of COVID-19-infected cancer patients: A retrospective case study in three hospitals within Wuhan, China. Ann Oncol. 2020 Jul;31(7):894-901.

27. Jaakkimainen RL, Bondy SJ, Parkovnick M, Barnsley J. How infectious disease outbreaks affect community-based primary care physicians: comparing the SARS and H1N1 epidemics. Can Fam Physician. 2014 Oct;60(10):917-25.

28. Shi S, Qin M, Shen B, Cai Y, Liu T, Yang F, et al. Association of Cardiac Injury With Mortality in Hospitalized Patients With COVID-19 in Wuhan, China. JAMA Cardiol. 2020 Mar 25;e200950.

29. Chen N, Zhou M, Dong X, Qu J, Gong F, Han Y, et al. Epidemiological and clinical characteristics of 99 cases of 2019 novel coronavirus pneumonia in Wuhan, China: a descriptive study. Lancet. 2020 Feb;395(10223):507-13.

30. Weissleder R, Lee H, Ko J, Pittet MJ. COVID-19 diagnostics in context. Sci Transl Med. 2020;12(546):1-7.

31. de Burgos-Lunar C, Salinero-Fort MA, Cárdenas-Valladolid J, et al. Validation of diabetes mellitus and hypertension diagnosis in computerized medical records in primary health care. BMC Med Res Methodol. 2011;11(1):146.

\section{Figures}




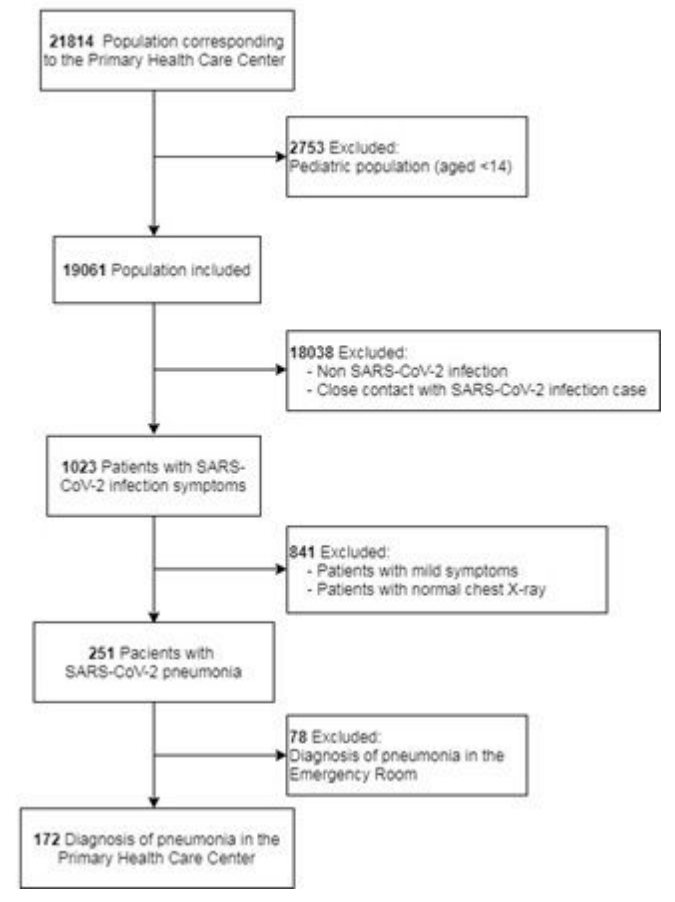

Figure 1

Flow chart

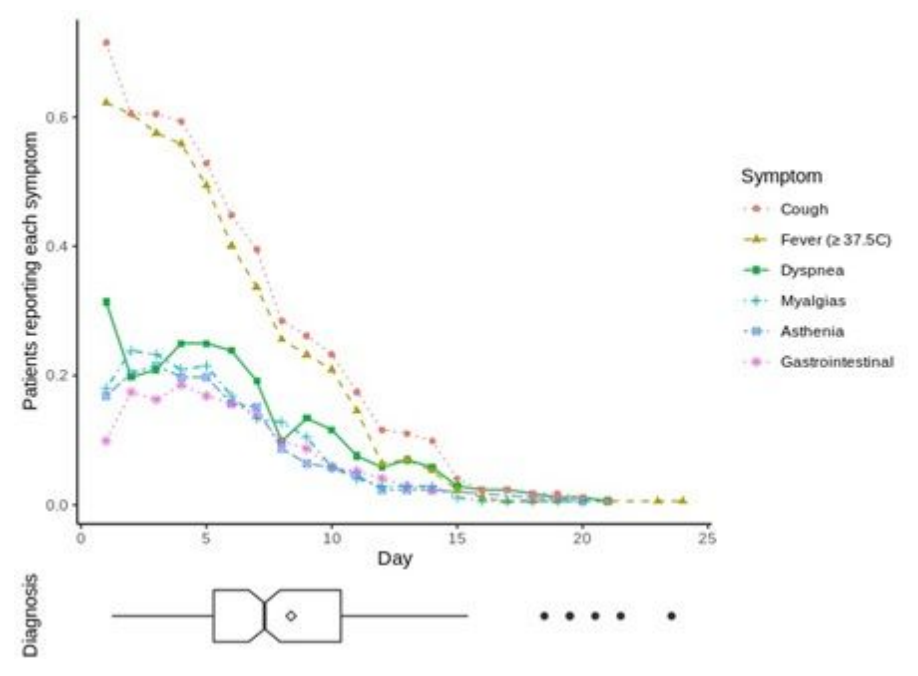

Figure 2

Chronological line of clinical manifestations in SARS-CoV-2 pneumonia in the whole sample ( $\mathrm{n}: 172)$ 


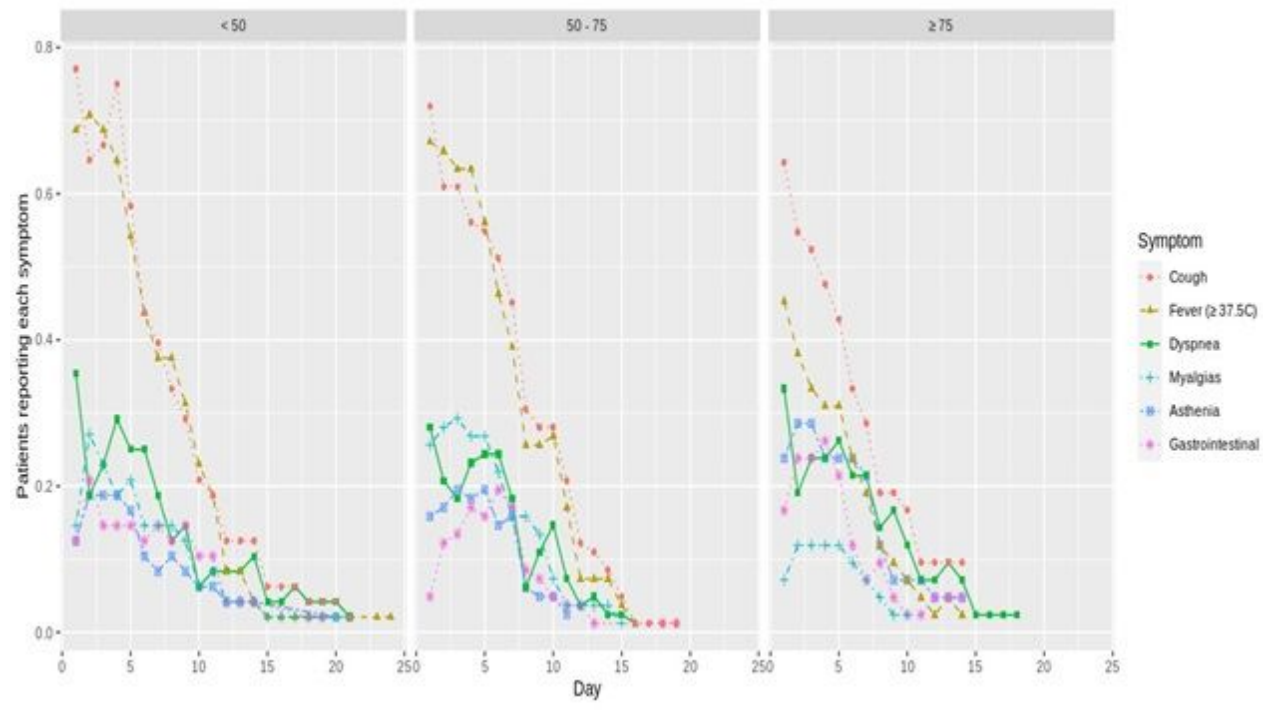

\section{Figure 3}

Chronological line of clinical manifestations in SARS-CoV-2 pneumonia in the whole sample (n: 172)

\section{Supplementary Files}

This is a list of supplementary files associated with this preprint. Click to download.

- Additionalfile1.docx 